\title{
Determinantes contextuais da coesão do sistema de crenças democrático: evidências a partir da América Latina
}

\section{Introdução}

Estudos recentes têm argumentado que a América Latina é um importante "laboratório" para os estudos sobre a legitimidade política (Booth \& Seligson, 2009). Ao mesmo tempo em que pertencem a "terceira onda de redemocratização" (Huntington, 1991) e compartilham de uma história relativamente homogênea advinda da colonização ibérica, existem muitas diferenças contextuais entre os países no que tange às suas experiências institucionais, desenvolvimento econômico e social. De que forma essas diferenças contextuais ajudam a explicar as atitudes democráticas dos latino-americanos?

$\mathrm{O}$ artigo baseia-se em dois argumentos centrais. Em primeiro lugar, que os fatores contextuais são relevantes para explicar as atitudes democráticas. Estudos anteriores já sinalizaram nessa direção, demonstrando que os anos contínuos de democracia, combinados a índices elevados de riqueza e desenvolvimento econômico estão relacionadas a maiores níveis de apoio à democracia, participação e tolerância política (Peffley e Rohrschneider,

\footnotetext{
1 Departamento de Ciências Políticas, Universidade Federal de Minas Gerais, Av. Antônio Carlos 6627. Belo Horizonte, MG, Brasil. E-mail: <mariofuks@gmail.com>

2 Pós-Graduação em Ciência Política, Universidade Federal de São Carlos Rod. Washington Luis, km 235. São Carlos, SP, Brasil. E-mail: <gacasalecchi@gmail.com>

3 Universidade Estadual de Maringá, Departamento de Ciências Sociais. Avenida Colombo, 5790 Jardim Universitário. Maringá, PR, Brasil E-mail: <ednaldoribeiro@icloud.com>
} 
2003; Booth e Seligson, 2009; Kotzian, 2011; Salinas e Booth, 2011; Yap, 2013). Indo além desses estudos, o segundo argumento é que os fatores contextuais importam não somente para a explicação das atitudes democráticas em geral, como também para o que chamaremos aqui de "coesão democrática" - a formação de um "sistema de crenças" democrático coerente, no qual as atitudes convergem para o apoio aos princípios democráticos.

Para testar essas hipóteses, utilizamos como fonte de dados o survey Barômetro das Américas de 2010, conduzido pelo Latin American Public Opinion Project - LAPOP. Para as variáveis contextuais, foram utilizados os índices de democracia do Polity $I V$ e as medidas de riqueza e de desenvolvimento econômico do World Bank.

$\mathrm{O}$ artigo está organizado em três seções. A primeira revisa a literatura sobre legitimidade democrática, com ênfase nos avanços na direção do conceito propomos, de sistema de crenças democrático. Ainda nessa seção, são apresentadas as medidas empíricas das atitudes democráticas e a construção de uma variável que representa a coesão do sistema de crenças democrático. A seção seguinte revisa a literatura dos determinantes das atitudes democráticas, com ênfase no efeito dos fatores contextuais, especialmente os fatores econômicos e políticos. A terceira seção apresenta os resultados da pesquisa e as suas implicações para a democracia na América Latina.

\section{Do apoio à democracia ao sistema de crenças democrático}

A legitimidade política é um dos componentes necessários para a consolidação dos regimes democráticos (Linz e Stepan, 1996; Diamond, 1999). Não poderia haver, ao menos a longo prazo, uma "democracia sem democratas" (Moisés, 2008). Portanto, um patamar mínimo de preferência pela democracia é fundamental para a estabilidade do regime. Por outro lado, as pesquisas não chegaram um consenso sobre quais atitudes, especificamente, seriam realmente importantes para a estabilidade e a consolidação democrática.

$\mathrm{O}$ artigo propõe um modelo multidimensional de atitudes democráticas, com o objetivo de substituir a medida mais 
simples de adesão à democracia por um conjunto articulado de valores e princípios democráticos, constituindo um "sistema de crenças". A ideia central é que as atitudes democráticas estão associadas a um sistema complexo de princípios, tal como o próprio conceito de democracia, que pode ser qualificada como "procedimental", "liberal", "participativa", entre outros adjetivos (Collier e Levitsky, 1997).

Essa proposta está no centro de um debate recente, que vem sendo desenvolvido pela literatura. De forma geral, as pesquisas sobre legitimidade democrática costumam medir o apoio ao regime com uma medida simples de preferência: prefere-se a democracia, apesar dos seus problemas, ou suas alternativas autoritárias (Rose, 2002). Tal abordagem têm sido criticada por pesquisas mais recentes. Em primeiro lugar, ela carrega um viés normativo, uma vez que as pessoas podem adotar uma atitude favorável à democracia simplesmente por acreditarem que essa seria uma resposta socialmente desejável (Booth \& Seligson, 2009). Outro problema refere-se à falta de clareza do significado substantivo dessa preferência. A democracia, propõe Rose (2002), é uma "tabula rasa" na qual os indivíduos atribuem os mais variados significados (Ottemoeller, 1998; Camp, 2001; Dalton, Sin. e Jou, 2007; Moisés, 2010). Isso faz com que seja muito difícil, para não dizer impossível, interpretar o sentido exato desse apoio manifestado (Bratton e Mattes, 2001; Carrión, 2008).

Por essa razão, Booth e Seligson (2009) aconselham não trabalhar com a pergunta direta de preferência à democracia, mas sim com perguntas indiretas ligadas aos princípios subjacentes ao regime democrático. Essa proposta minimiza os problemas derivados do viés normativo e vincula seu significado a um conteúdo específico.

Além disso, e ainda mais importante, esse tipo de abordagem permite a construção de modelos mais complexos das atitudes de apoio à democracia, a partir do entendimento de que esse apoio tem como referência não somente o regime político, mas às diversas dimensões que o compõe (Schedler e Sarsfield, 2007). Um cidadão pode apoiar um princípio democrático básico, como as eleições 
para a escolha dos governantes, mas, ao mesmo tempo, afastar-se de outro princípio elementar, como o da tolerância política. Justamente por apresentarem esse tipo de "ambivalência", Carlin e Singer (2011) argumentam que:

Para esse cidadão hipotético, as dimensões subjacentes do apoio não são lineares, mas agrupadas categoricamente. Ao pontuar esse cidadão no meio de uma escala linear unidimensional - menos democráticos que os "democratas" e mais democráticos que os "não democratas" - obscurece uma grande quantidade de informação potencialmente e teoricamente relevante"4 (Carlin e Singer, 2011:1503).

$\mathrm{O}$ artigo adere a essa perspectiva multidimensional do apoio à democracia. De fato, se a democracia é um fenômeno complexo e multifacetado, igualmente complexa e multifacetadas são as atitudes a ela associadas. Propõe-se, a partir dessa perspectiva, analisar o apoio à democracia como um "sistema de crenças democrático", em um sentido semelhante àquele atribuído por Converse (1964) à ideologia política. Em outras palavras, buscamos aqui compreender o efeito dos contextos nacionais sobre a capacidade do cidadão em conferir sentido ao seus "sistema de crenças democrático", isto é, de sustentar atitudes coerentemente "democráticas", convergentes aos princípios da democracia.

Para avançar na construção do modelo de análise, o primeiro passo é identificar e operacionalizar os princípios nucleares da democracia. Nesse sentido, escolhemos cinco princípios democráticos: eleições livres e competitivas, participação política, independência e separação dos poderes, estado de direito e tolerância política.

O primeiro princípio é um dos pilares da democracia moderna. Não existe, hoje, democracia sem eleições livres, periódicas e

4 Tradução livre de:"For this hypothetical citizen, the underlying dimensions of support are not linear but bundled categorically. Scoring this citizen in the middle of a linear single-dimension democracy scale-less democratic than "democrats" and more democratic than "nondemocrats"—obscures a great deal of potentially theoretically relevant information". 
competitivas (Schumpeter, 1975; Sartori, 1999; Alvarez et. al., 1996; Linz e Stepan, 1996; Bobbio, 1994). No Barômetro das Américas, uma pergunta que corresponde a essa dimensão é: “existem pessoas que dizem que precisamos de um líder forte, que não seja eleito através do voto. Outros dizem que, ainda que as coisas não funcionem, a democracia eleitoral, ou seja, o voto popular, é sempre o melhor". Haviam duas respostas, que foram recodificadas em: (0) necessitamos de um líder forte que não seja eleito através do voto; e (1) a democracia eleitoral é a melhor.

A participação política é outro princípio central da democracia, que pode ocorrer tanto por meio do voto, como também considerando o repertório de ações pelo qual os cidadãos podem vocalizar suas preferências (Verba, Schlozman e Brady, 1995). Para essa variável utilizamos a seguinte pergunta disponível no Barômetro das Américas 2010: "até que ponto o Sr.(a) aprova ou desaprova a participação de pessoas em manifestações permitidas por lei”. As respostas podem variar entre desaprova muito (1) à aprova muito (10). Entretanto, para que pudessem ser comparadas às demais variáveis, optamos por recodificá-la como uma variável binária: baixo apoio (de 1 a 7 ) e alto apoio (de 8 a 10) ${ }^{5}$.

Desde a obra clássica de Montesquieu, um aspecto constitutivo do governo representativo e, posteriormente, da democracia é a independência dos poderes e os mecanismos de "freios e contrapesos". Em um regime democrático, Executivo, Legislativo e Judiciário têm funções e limites determinados pela Constituição. Para medir a adesão a esse princípio, utilizamos a seguinte pergunta: "você acredita que quando o país está enfrentando dificuldades é justificável que o presidente da república feche o Congresso e governe sem o Congresso". Existiam apenas duas alternativas de resposta que foram recodificadas da seguinte maneira: (0) sim, justifica-se e (1) não, não se justifica.

5 A escolha de um ponto de corte "exigente" na elaboração do constructo do "sistema de crenças democrático" segue a orientação geral do modelo, de considerar como democrata coeso apenas aquele com as pontuações mais altas. Dessa forma, distinguimos com clareza o "democrata coeso" (apenas aquele que atinge as pontuações mais altas em todas as variáveis que compõem o sistema de crenças) do democrata cujo sistema de crenças não é coeso. 
Outro princípio constitutivo da democracia contemporânea é o primado da lei. Em uma democracia, as decisões tomadas de forma coletiva são transformadas em normas de direito vinculativas, ou seja, que devem ser respeitadas por todos os cidadãos (Bobbio, 1994). Essas normas asseguram que as decisões coletivas não sejam suprimidas pelas vontades individuais e que prevaleça a lei ao invés das "paixões" (O’Donnel, 2004). Para medir essa dimensão, utilizamos a pergunta: "para poder prender criminosos, você acredita que as autoridades devem sempre respeitar as leis ou que, em certas ocasiões, as autoridades podem agir sem respeitar a lei". Haviam duas respostas que foram recodificadas em: (0) em certas ocasiões podem agir sem respeitar a lei e (1) devem sempre respeitar a lei.

Por fim, incluímos no modelo de sistema de crenças democrático, a tolerância política. $\mathrm{O}$ respeito à divergência, em especial às opiniões minoritárias, é um aspecto constitutivo do ambiente democrático. Em um ambiente marcado pela intolerância as pessoas não têm oportunidade de expor as suas opiniões de forma igualitária e nem debater publicamente suas ideais (Dahl, 1997). Essa última dimensão foi construída com base na seguinte pergunta: "existem pessoas que sempre falam mal da forma de governo do Brasil, não somente do governo atual, mas sim da forma de governo, o quanto você aprova ou desaprova o direito de votar dessas pessoas". As opções de respostas eram as mesmas da dimensão da participação, variando de desaprova muito (1) para aprova muito (10). Optamos em recodificá-las de forma dicotômica, obedecendo o mesmo corte da participação.

Como pensar esses princípios democráticos como parte de um sistema de crenças? Há mais de meio século, Campbell e seus colaboradores (1960) reformularam a ideia de cognição política, incluindo, para além de seu conteúdo específico, a sua estrutura. Converse (1964) aprofundou essa ideia a partir do conceito de "sistema de crenças" ideológico, o qual poderia ser mais ou menos coeso, em função da consistência das atitudes.

Trazendo esse conceito para o presente estudo, consideramos que um sistema de crenças democrático é coeso apenas quando 
todas as atitudes de um indivíduo são democráticas, ou seja, quando ele apoia as eleições, a participação, a independência dos poderes, o primado da lei e também quando é tolerante. Em termos operacionais, criamos inicialmente uma escala com o somatório de todas as variáveis de apoio aos princípios democráticos. Como todas as variáveis são binárias, o resultado é uma escala que vai de 0 a 5, indicando graus crescentes de coesão. Pode-se identificar nessa escala três tipos de coesão: a de quem não pontou, e que poderíamos chamar de "autoritários coesos"; quem fez a pontuação máxima, os "democratas coesos"; e as variações intermediárias (de 1 a 4), que adere a um ou mais princípios, mas não todos e, por essa razão, são chamados de "democratas não coesos".

\section{Condicionantes contextuais e individuais da coesão democrática}

Tendo construído a medida de coesão das atitudes democráticas, passamos à explicação do fenômeno: o que faz com que alguns cidadãos tenham um sistema de crenças democrático coeso enquanto outros um sistema inconsistente? Embora quase não haja pesquisas específicas sobre a coesão das atitudes democráticas, existe uma longa tradição de pesquisa sobre o apoio à democracia para nos auxiliar na elaboração de hipóteses.

No que se refere a atributos individuais, as pesquisas em comportamento político têm reiterado o efeito do interesse político e da educação sobre as atitudes políticas. Nos estudos sobre legitimidade democrática, essa relação é bem documentada na literatura e demonstra que o interesse por política e os anos de estudo promovem atitudes democráticas, incluindo o apoio à democracia (Norris, 1999; Dalton, 2004; Booth e Seligson, 2009) e tolerância (Gibson et. al., 1992) e participação (Verba et. al., 1995; Delli Carpini e Keeter, 1996). Estes resultados valem tanto para novas (Evans e Rose, 1997; Moisés e Carneiro, 2008; Booth e Seligson, 2009) como velhas democracias (Dalton, 1999; Dalton, 2004). Com base nesse estudos, nossa hipótese é que, no nível individual, a escolaridade e 
o interesse por política sejam os principais determinantes da coesão do sistema de crenças democrático.

Para controlar o efeito da escolaridade e do interesse por política, acrescentamos ao modelo variáveis que, segundo a literatura, também estão relacionadas com as atitudes democráticas, tais como: as características socioeconômicas e demográficas, a avaliação da economia, a confiança interpessoal (Norris, 1999; Dalton, 2004; Moisés, 2008; Moisés e Carneiro, 2008; Booth e Seligson, 2009; Salinas e Booth, 2011).

A hipótese principal, no entanto, é que os fatores contextuais nacionais também exercem um efeito relevante sobre a coesão dos sistema de crenças democrático. Uma das abordagens mais influentes para explicar o impacto do contexto sobre as atitudes políticas é a teoria da modernização, segundo a qual o desenvolvimento econômico tem um efeito, ao menos indireto, sobre as crenças e valores políticos. A modernização seria importante porque aumenta os níveis de educação, expande a classe média (considerada, desde Aristóteles, uma condição para a estabilidade da democracia) e profissionais qualificados e incentiva a mobilidade social e geográfica e a urbanização (Lipset, 1959; Inglehart e Welzel, 2006). Além disso, ela cria um ambiente favorável para a expansão dos sistemas de comunicação nacionais (Norris, 2011), promovendo um maior fluxo e acesso à informação.

De forma geral, as pesquisas empíricas mais recentes têm apoiado a tese da modernização. Salinas e Booth (2011), por exemplo, demonstram com dados da América que o PIB per capita tem um efeito positivo e significativo na preferência pela democracia, no apoio à participação política, bem como na tolerância com os críticos do regime. Nas três áreas atitudinais, o PIB se mostrou um componente explicativo importante, mesmo com o controle das demais variáveis. Em outro estudo, Huang et. al. (2008) também encontram um efeito positivo do PIB per capita sobre a preferência pela democracia.

É importante ressaltar, no entanto, que algumas pesquisas contrariam esses achados. Utilizando os dados do WVS, Magalhães (2014) 
encontrou uma associação negativa entre o apoio à democracia e o PIB per capita quando este último é controlado por uma medida de accountability dos governos. Também com dados do WVS, Kotzian (2011) encontrou um efeito reduzido do PIB per capita sobre sua medida de legitimidade democrática, quando controlado por crescimento econômico e desigualdades sociais.

Apesar das divergências na literatura, e concordando que outros fatores econômicos (como o crescimento econômico) e políticos (como a qualidade da democracia) podem moderar o efeito da riqueza nacional sobre as atitudes democráticas, baseamos nossa hipótese no estudo de Salinas e Booth (2011) que estudam, como nós, o caso específico da América Latina. Nesse sentido, a nossa hipótese é que a modernização, medida por meio do PIB per capita, tenha um efeito consistente e positivo sobre a coesão das atitudes democráticas.

Outro aspecto importante na explicação das atitudes democráticas é o contexto político (Bratton e Mattes, 2001; Evans e Whitefield, 1995). Pesquisas recentes têm chamado a atenção para duas variáveis em particular: a duração e a qualidade das democracias. Por um lado, o tempo é importante para que as instituições amadureçam (Dahl, 1997), consolidando e aperfeiçoando suas regras formais e informais, e desenvolvendo símbolos e exemplos históricos que conformem uma cultura política democrática.

Rustow (1970:358) argumenta que um dos passos necessário nas transições democráticas é a "habituação". Nessa fase, tanto os políticos como os cidadãos aprendem com a resolução dos problemas e depositar sua fé nas novas regras e, em seguida, aplicá-las a problemas futuros. Ao longo do tempo, as crenças e os comportamentos se tornam hábitos praticados naturalmente, consolidando uma rotina ou tradição.

É nesse sentido que Salinas e Booth (2011), em seu estudo na América Latina, argumentam que um país com mais anos de democracia acumulados cria condições favoráveis para a formação das atitudes democráticas. De acordo com eles, essa medida de "anos de democracia" seria uma proxy para o processo que eles chamam de 
“aculturação", referindo-se exatamente a esse aprendizado social no qual as normas de uma sociedade são introjetadas seus indivíduos: "nós medimos o número total de anos de governo democrático desde 1950, o que nos permitiu sondar o grau em que pode ter ocorrido aculturação às regras do jogo democrático nas últimas décadas"' (Salinas e Booth, 2011:40). O resultado da pesquisa confirma essa relação. Os autores encontraram um efeito positivo e estatisticamente significativo dos anos de democracia de um país sobre três diferentes atitudes: a preferência pela democracia, o apoio à participação e a tolerância aos críticos do regime, mesmo quando controlados por outras variáveis contextuais e individuais.

Mattes e Bratton (2007:204) chegam a conclusão semelhante ao estudar os países africanos: "os resultados também evidenciam um forte impacto a longo prazo dos legados dos regimes sobre a aprendizagem política (...) um legado de competição multipartidária, mesmo continua ou ininterrupta, tem um forte efeito positivo sobre o nível de demanda democrática". É importante notar, como fazem os autores, que o "aprendizado coletivo" ultrapassa os efeitos geracionais que, em seu modelo, não obteve nenhuma significância estatística: "independentemente da idade ou coorte geracional, as pessoas que vivem em países com legados institucionais semelhantes aprendem lições similares que influenciam a forma como eles enxergam a democracia"” (Mattes e Bratton, 2007:205).

Mas não é só o tempo de duração da democracia que importa, mas também a qualidade das suas instituições nesse período. Enquanto uma primeira geração de estudos sobre democratização esteve focada em compreender a transição dos regimes políticos e em que medida uma nação era ou não uma democracia, uma segunda geração tem avançado na direção de quão diferentes são as democracias em termos de sua qualidade. De acordo com Magalhães (2014), a qualidade da democracia é um fator fundamental na

6 Tradução livre de: "we measure the total number of years of democratic rule since 1950 in each country"

7 Tradução livre de:"Regardless of age, or generational cohort, people living in countries with similar institutional legacies learn similar lessons that influence how they see democracy. 
formação das atitudes, porque representam o contexto no qual os cidadãos interagem. Se a democracia sustenta instituições funcionais e eficazes, é plausível supor que os cidadãos que vivam nessas democracias tenham atitudes mais positivas do que aqueles que vivem no contexto oposto, em que as instituições são falhas e incapazes de cumprirem suas finalidades.

Para medir a qualidade da democracia, utilizamos a medida do Polity IV que, apesar de sofrer criticas (Mainwaring et. al. 2001), continua a ser uma das mais consistentes e utilizadas na área. A medida é construída combinando-se dois indicadores que medem tanto aspectos autoritários quanto democráticos dos regimes democráticos. O indicador final é uma medida que varia de -10 (mais autoritário) a 10 (mais democrático).

Quanto ao tempo de democracia, utilizamos outra variável disponibilizada pelo Polity IV e que mede os anos ininterruptos de um regime político desde sua última transição. Trata-se, portanto, de uma medida de estabilidade democrática, que tem como referência o tempo transcorrido desse regime sem interrupções (golpes, etc.).

\section{Resultados e discussão}

Quão democráticos são os latino-americanos? Se tomarmos como referência uma atitude de preferência pela democracia, a resposta seria positiva: 78,5\% afirmam que a democracia é preferível a qualquer outra forma de governo. O cenário fica mais complexo, no entanto, quando o critério são as atitudes relativas aos princípios democráticos e a coesão dessas atitudes, conforme mostra a Figura 1. Nota-se que algumas atitudes têm um percentual ainda mais elevado que a própria preferência pela democracia, como é o caso do apoio às eleições livres e competitivas $(87,4 \%)$ e da separação dos poderes $(85,3 \%)$. Outras, no entanto, têm baixo apoio. É o caso do apoio ao estado de direito $(58,6 \%)$, do apoio à participação em manifestações pacíficas $(49,1 \%)$ e, sobretudo, a tolerância política 33,8\%). 
Figura 1 - Preferência pela democracia e apoio às dimensões democráticas

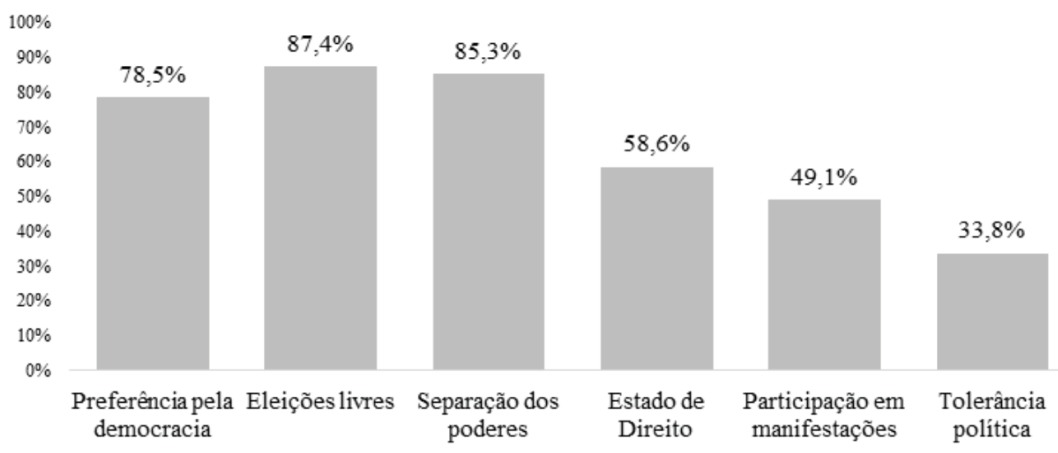

A Figura 2, por sua vez, mostra quantas das atitudes analisadas são democráticas, isto é, de apoio aos princípios democráticos. Uma boa notícia para a legitimidade das democracias na região é que o percentual de autoritários coesos, que não apoiam nenhuma dimensão da democracia, é quase inexistente, compondo menos de $1 \%$ da população. A má notícia, no entanto, é que os democratas coesos também são poucos, cerca de $12,8 \%$. Ou seja, a grande maioria da população latino-americana está distribuída entre os democratas não coesos, que somam $86,6 \%$; sendo que 6,0\% apoiam apenas uma dimensão democrática, 21,8\% apoiam duas, 33,9\% apoiam três e outros $24,8 \%$ apoiam quatro dimensões.

Figura 2 - Distribuição do grau de coesão das atitudes democráticas

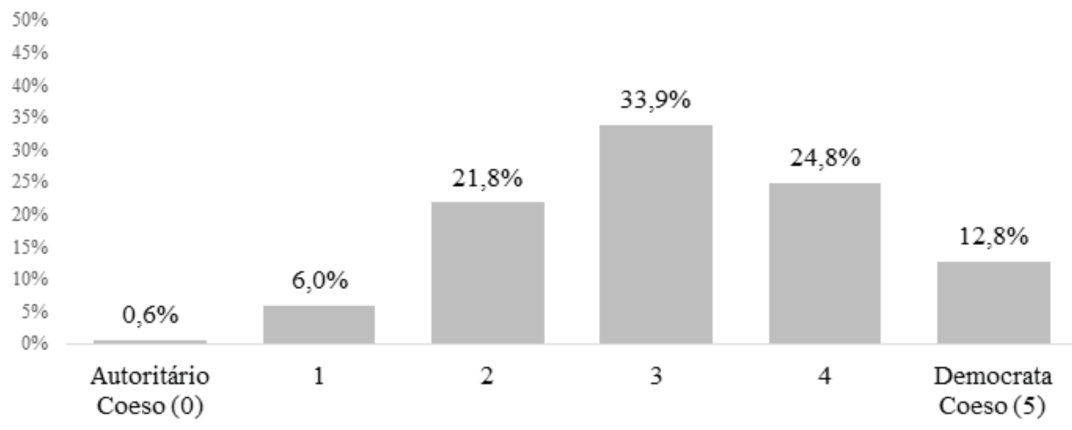


Percebe-se o hiato que existe entre a adesão à democracia e sua consistência quando se considera suas várias dimensões. Se a preferência pela democracia é uma atitude consolidada na região, o mesmo não pode ser dito do apoio às normas e valores democráticos. Já há algum tempo estudos sobre comportamento político falam da ambivalência dos cidadãos (Converse, 1964; Zaller, 1992; Feldman e Zaller, 1992). Mais recentemente, os ambivalentes também foram alvo de estudos sobre a legitimidade democrática no Brasil e na América Latina (Moisés, 2008; Carrión, 2008). Os resultados aqui apresentados apontam a presença de um fenômeno dessa mesma natureza: um sistema de crenças democrático pouco coeso, em que os cidadãos endossam alguns princípios democráticos e rechaçam outros.

Outro fator que chama a atenção é a grande variação entre os países, conforme mostra a Figura 3. O país com maior percentual de democratas coesos é a Argentina (30\%), seguida do Uruguai (27\%) e da Costa Rica (26\%). Além desses países, Venezuela, Brasil e Jamaica têm percentuais acima dos 20\%. Do lado oposto, no entanto, estão El Salvador (5\%), Honduras (3\%) e o Haiti (2\%). Bolívia e Peru também têm percentuais bastantes baixos, com menos de $5 \%$ cada um deles. Ou seja, há uma diferença de mais de $28 \%$ entre o país com o maior percentual de democratas coesos (Argentina) e o menor (Haiti).

Figura 3 - Percentual de democratas coesos na América Latina

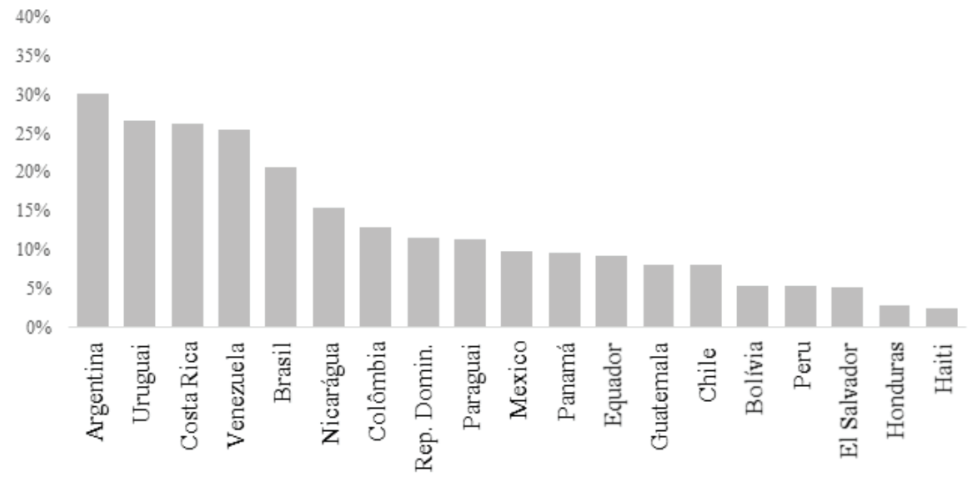


Esses números reforçam nossa suspeita de que o contexto de cada país tenha um papel explicativo forte na coesão das crenças democráticas na região. Para testar estatisticamente essa hipótese, estimamos o coeficiente de correlação intraclasse, que demonstra o quanto a variável dependente é explicada pelos fatores de nível individual e pelo contexto (Raudenbush e Bryk, 2002). O resultado é que $8,6 \%$ da variação da coesão das atitudes democráticas é explicada pelo nível macro, ou seja, por variáveis contextuais dos países.

Se o contexto é relevante para a explicação da coesão das atitudes democráticas, resta saber quais são as características desse contexto que fazem a diferença. Nossas hipóteses, como discutido na seção anterior, são que o desenvolvimento econômico, a qualidade da democracia e os anos ininterruptos de democracias são importante determinantes da coesão, apresentando um efeito positivo e estatisticamente significativo sobre ela.

Como nosso principal objetivo é testar a diferença entre democratas coesos e não coesos, e como os autoritários coesos compõe uma parcela inexpressiva da população, optamos por excluí-los da análise. Nossa variável dependente é uma variável binária que separa os "democratas coesos", que apoiaram todas as dimensões da democracia, dos "não coesos", que não apoiaram ao menos uma das dimensões da democracia ${ }^{8}$. Dessa forma, utilizamos um modelo de regressão logística multinível. A Tabela 1 apresenta os resultados do modelo:

Tabela 1 - Determinantes da coesão no sistema de crenças democrático. Regressão Logística Multinível

\begin{tabular}{cccc}
\hline & Coeficiente & Erro Padrão & Significância \\
\hline Variáveis individuais & & & \\
\hline Homem & $-0,01$ & 0,039 & 0,79 \\
\hline De 18 a 24 anos & Referência & Referência & Referência \\
\hline De25 a 34 anos & 0,15 & 0,059 & 0,01 \\
\hline De35 a 44 anos & 0,29 & 0,061 & 0,00 \\
\hline
\end{tabular}

8 Nós também realizamos testes com uma variável dependente continua de "democratismo", ou seja, a soma das atitudes democráticas. Os resultados foram muito similares ao modelo logístico, com a variável binária. 


\begin{tabular}{|c|c|c|c|}
\hline De 45 a 60 anos & 0,38 & 0,060 & 0,00 \\
\hline Mais de 60 anos & 0,44 & 0,076 & 0,00 \\
\hline Vive em área urbana & 0,00 & 0,051 & 0,96 \\
\hline Riqueza (posse de bens) & 0,03 & 0,011 & 0,01 \\
\hline Escolaridade em anos & 0,06 & 0,006 & 0,00 \\
\hline Tem interesse por política & 0,26 & 0,041 & 0,00 \\
\hline Alta confiança interpessoal & 0,35 & 0,044 & 0,00 \\
\hline Avalia bem a economia & 0,13 & 0,048 & 0,01 \\
\hline \multicolumn{4}{|l|}{ Variáveis contextuais } \\
\hline PIB per capita (R\$1.000) & 0,10 & 0,029 & 0,00 \\
\hline Qualidade da democracia & $-0,02$ & 0,046 & 0,62 \\
\hline Tempo de democracia & 0,01 & 0,007 & 0,09 \\
\hline Constante & $-4,37$ & 0,373 & 0,00 \\
\hline Total de observações (nível 1) & & 26861 indivíduos & \\
\hline Total de observações (nível 2) & & 19 países & \\
\hline
\end{tabular}

Fonte: Barômetro das Américas 2010

Embora o principal objetivo do artigo seja testar o nível contextual, cabem algumas observações a respeito dos atributos dos indivíduos, especialmente a escolaridade e o interesse por política. Reforçando o papel atribuído a essas variáveis nos estudos clássicos sobre comportamento político e legitimidade democrática, nosso modelo não deixa dúvidas de que quanto mais anos de estudo e quanto maior o interesse por política, maiores são as chances de um indivíduo ser um democrata coeso. A centralidade dessas variáveis sugere que tanto fatores educacionais como motivacionais contribuem para a formação de cidadãos mais democráticos, não apenas em relação à sua preferência pelo regime, mas também no reconhecimento e no apoio coerente aos seus diferentes princípios subjacentes.

Outro resultado relevante refere-se ao efeito da idade, sendo que as chances de ser um democrata coeso aumentam à medida em que as faixas etárias se tornam mais velhas. Esse resultado é instigante, pois contraria a ideia de que os mais jovens teriam maior propensão a desenvolver atitudes democráticas. No caso específico da América Latina, os dados apontam na direção oposta: os mais velhos têm um perfil mais democrático do que os jovens. Uma explicação plausível (Lagos e Moreno, 2013) é que as gerações mais velhas são justamente aquelas que experimentaram as atrocidades militares e as que 
vivenciaram a luta por eleições diretas, direitos políticos e sociais. Nesse sentido, elas teriam enraizado os valores democráticos de forma mais sólida do que as gerações posteriores, que viveram só na democracia e que não participaram do processo de transição.

A confiança interpessoal e a avaliação da economia também tiveram efeitos positivos sobre a coesão das crenças democráticas. O primeiro resultado endossa estudos clássicos como o de Almond e Verba (1964) e Putnam (1996) que ressaltavam a importância da confiança na formação de uma cultura cívica, própria à democracia. O segundo parece reforçar resultados que demonstram que, especialmente em novas democracias, o apoio ao regime democrático tem caráter instrumental, no qual os cidadãos apoiam o regime quando este atende suas demandas econômicas imediatas (Bratton e Mattes, 2001).

O que dizer das variáveis contextuais? Das três variáveis abordadas nesse estudo, duas tiveram um efeito significativo: o desenvolvimento econômico (PIB) e os anos ininterruptos de democracia desde a última transição política. Pode-se observar pela tabela que ambas as variáveis aumentam as chances da coesão democrática, de forma estatisticamente significativa ${ }^{9}$. Por outro ladro, ao contrário do que esperávamos, a qualidade da democracia, medida pelo índice do Polity IV não apresentou significância.

As Figuras 2 e 3 apresentam os efeitos marginais das duas variáveis contextuais que apresentam significância estatística no modelo, dando uma ideia mais precisa do seu efeito. Mantendo-se as demais variáveis constantes em suas médias, a probabilidade de ser um democrata coeso em um pais cujo PIB per capital não é maior do que $\$ 1.000$ é de $7 \%$. O acrescimento de $\$ 1.000$ ao PIB aumenta em $1 \%$ essa probabilidade, tornando-a de $8 \%$. Em um país de PIB per capita de até $\$ 10.000$ a probabilidade aumenta para $13 \%$ e considerando o maior PIB per capita dos países aqui estudado, de $\$ 15.000$, a probabilidade chega a $18 \%$.

9 Consideramos aqui um limite de significância a p >0,10. Apesar de alto, consideramos esse limite justificável, tendo em vista a natureza multinível do modelo, no qual o número de caso de países é necessariamente baixo. 
Figura 4 - Efeitos marginais do PIB per capita sobre ser um democrata coeso

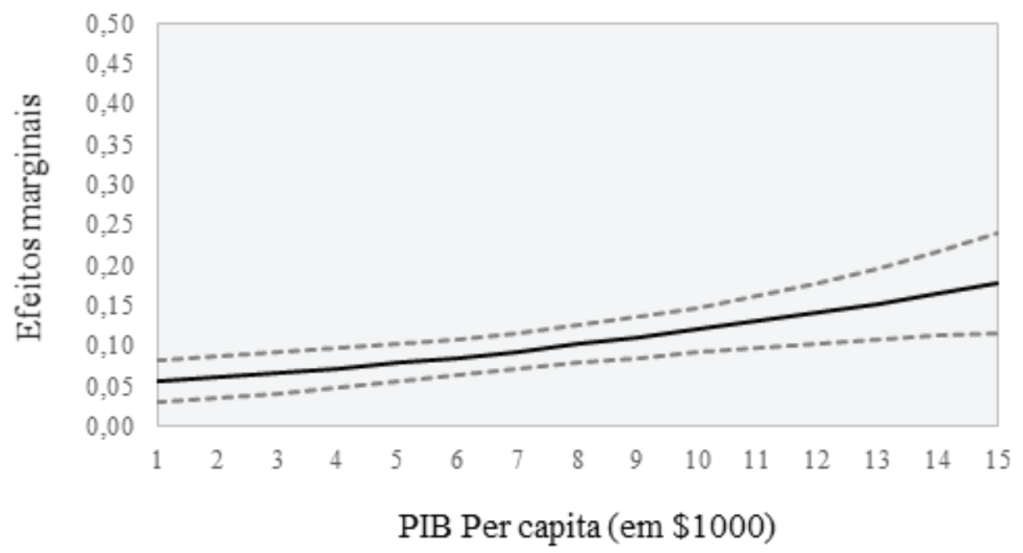

Fonte: Barômetro das Américas 2010

Esse resultado reforça a teoria da modernização desenvolvida por Lipset (1959) e retomada em estudos mais recentes (Inglehart e Welzel, 2006; Kotzian, 2011; Yap, 2013), de que o desenvolvimento econômico tem impacto relevante sobre as atitudes dos cidadãos. O processo mediante o qual o PIB aumenta a coesão do sistema de crenças democrático merece uma investigação mais cuidadosa. Possivelmente ele ocorre por meio de uma série de mecanismos indiretos associados a ele, entre os quais se destacam: a consolidação de um sistema nacional de comunicação, a ampliação e qualificação do sistema educacional, a mobilidade social e a urbanização (Lipset, 1959; Norris, 2011).

O segundo fator contextual relevante para explicar a coesão são os anos ininterruptos de democracia. $\mathrm{O}$ efeito marginal de um latino-americano que viva num país com menos de um ano da sua última transição é de apenas 10\%, mantendo-se as demais condições constantes em suas médias. Ao completar 30 anos de democracia, essa probabilidade aumenta, praticamente, $50 \%$, atingindo cerca de $15 \%$. Se a democracia persiste sem interrupções até os 60 anos, a probabilidade de ser um democrata coeso se aproxima de $20 \%$. Como existem poucos casos de democracias com mais de 60 anos 
ininterruptos na América Latina, o intervalo de confiança aumenta bruscamente desse período em diante.

Figura 5 - Efeitos marginais dos anos ininterruptos de democracia sobre ser um democrata coeso

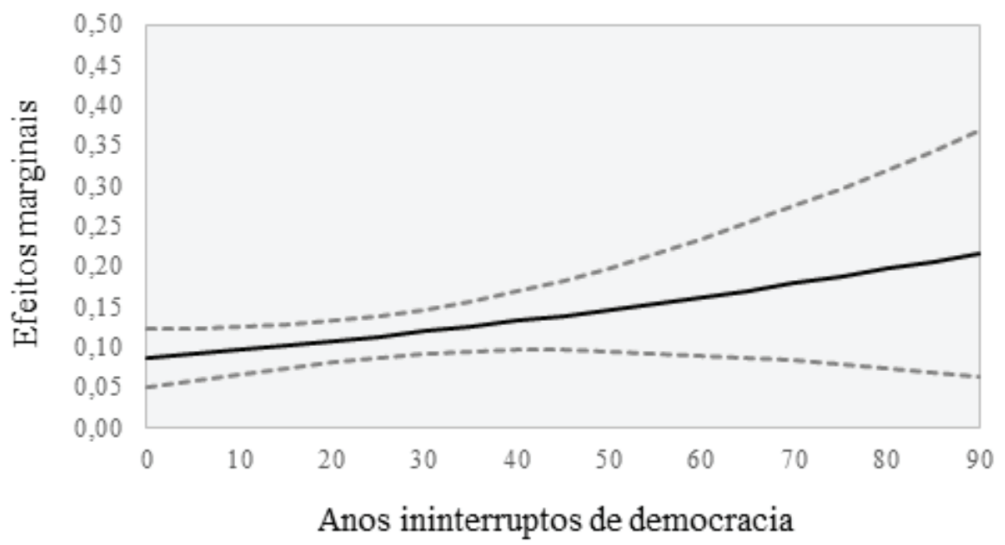

Fonte: Barômetro das Américas 2010

Esse resultado vai ao encontro das pesquisas que enfatizam a importância do funcionamento continuo das instituições democráticas para a disseminação de valores democráticos (Booth e Seligson, 2009; Salinas e Booth, 2011). No caso da América Latina, nosso estudo mostra que a tradição democrática importa não apenas adesão ao regime democrático, como também para a formação de um sistema de crenças democrático consistente, com o apoio simultâneo às suas diversas dimensões.

Por outro lado, surpreende-nos o fato da qualidade da democracia não ter qualquer efeito sobre as chances do indivíduo ser um democrata coeso, contrariando resultados de pesquisas anteriores em relação ao efeito sobre a preferência democrática (Magalhães, 2014). Ainda assim, é preciso ter cuidado na interpretação desse resultado, pois existe uma forte correlação $(0,500)$ entre os anos de democracia e a sua qualidade. De forma geral, as democracias mais 
antigas são, também, as que funcionam melhor, de acordo com os critérios do Polity IV. Uma análise que inclua efeitos indiretos pode revelar, por exemplo, que estabilidade do regime depende da qualidade da democracia.

Esses resultados apontam para um diagnóstico ao mesmo tempo otimista e preocupante para a legitimidade democrática na América Latina. Por um lado, o fato de a duração da democracia ser uma variável relevante para a explicação das atitudes democráticas coloca, por si só, um desafio para as jovens democracias. Ainda não existe, nessas condições, a "habituação", nem das elites políticas, nem das massas, o que torna a nova ordem democrática mais incerta. Por outro lado, uma vez superada as dificuldades iniciais, a própria democracia "em marcha" contribui para o seu fortalecimento. Esse resultado mostra a formação de um "estoque" de democracia, a partir da maturação das instituições e da experiência democrática, já contribui para a formação de um sistema coeso de crenças democrático, mesmo quando as instituições não apresentam a qualidade desejável.

Em síntese, os testes apontam que, ao adquirirem prosperidade e estabilidade, as democracias aumentam as chances de formar cidadãos com atitudes coerentemente democráticas. O contrário, no entanto, também procede: o baixo desenvolvimento econômico e a instabilidade democrática podem formar um contexto pouco favorável para que os cidadãos tenham um sistema de crenças democrático coerente.

\section{Considerações finais}

Embora o Barômetro das Américas de 2010 aponte que a maioria dos latino-americanos prefere a democracia, apenas um grupo reduzido apoia integralmente os princípios subjacentes a esse regime político. Mas o que explica a diferença entre aqueles que apoiam consistentemente os princípios democráticos e os que apoiam de forma inconsistente? Nossa análise dos dados, apontou a relevância de inúmeros atributos individuais, desde aqueles consagrados pela literatura, como a escolaridade e o interesse por política, como 
outros também esperados, tais como a confiança interpessoal e a avaliação positiva da economia do país. Nosso principal objetivo, no entanto, era testar os efeitos contextuais sobre a coesão, tópico ainda pouco explorado na literatura. Os resultados confirmaram parte de nossas expectativas. Primeiro, o desenvolvimento econômico importa não apenas na preferência pelo regime, mas também no apoio ao conjunto dos princípios democráticos. Além disso, à medida que a democracia amadurece, as atitudes cristalizam-se de forma coerente.

Apesar dos avanços apresentados nesse artigo, ainda restam importantes lacunas a serem preenchidas a partir dessa agenda de investigação. Em primeiro lugar, nesse estudo não exploramos a singularidade de cada uma das atitudes que constituem o sistema de crenças democrático. $\mathrm{O}$ alto número de ambivalentes deixa claro que essas diversas dimensões têm dinâmicas distintas e, portanto, merecem ser investigadas individualmente.

Devemos também lembrar que nossos resultados são válidos apenas para o contexto da América Latina. Seria útil replicá-los em outras regiões. $\mathrm{O}$ ideal seria ampliar a amostra e produzir maior variabilidade entre os países, comparando a coesão democrática e seus determinantes em democracias novas e antigas. A expansão do número de casos no segundo nível também permitiria testar um conjunto mais amplo de fatores contextuais, como corrupção, desigualdade econômica e fragmentação étnica.

Em resumo, ainda há um vasto terreno a ser explorado. Este tipo de pesquisa pode contribuir não apenas para a velha discussão sobre a estabilidade das democracias, mas também para a discussão mais recente sobre sua qualidade. Afinal, se a legitimidade é necessária para a consolidação democrática (Linz e Stepan, 1996), não seria importante a difusão de um sistema de crenças democrático coeso para aperfeiçoar o sistema político? 


\section{Referências bibliográficas}

Almond, G. A., e Verba, S. (1963). The civic culture: political attitudes and democracy in five nations. Princeton, NJ: Princeton University Press.

ALVAREZ, Mike; CHEIBUB, José Antônio; LIMONGI, Fernando; PRZWORSKI, Adam. (1996). "Classifying Political Regimes". Journal of Studies in Comparative International Development, v. 31, n. 2, p. 3-36.

BOBBIO, Norberto. (1994), Liberalismo e democracia. 6a edição, São Paulo, Brasiliense.

BOOTH, John e SELIGSON, Mitchell. (2009), The legitimacy puzzle: democracy and political support in eight Latin American nations. Cambridge, UK, Cambridge University Press.

BRATTON, Michael e MATTES, Robert (2001). "Support for democracy in Africa: Intrinsic or instrumental?" British Journal of Political Science, v. 31, n. 3 p. 447-474.

CAMP, Roderic. (2001), Citizens' views of democracy in Latin America. Pittsburgh, PA, University of Pittsburgh Press.

CAMPBELL, Angus; CONVERSE, Philip; MILLER, Warren; e STOKES, Donald. (1960), The American voter. New York, John Wiley.

CARLIN, Ryan e SINGER, Matthew (2011). "Support for polyarchy in the Americas". Journal of Comparative Political Studies, v. 44, n. 11, p. 1500-1526.

CARRIÓN, Júlio. F. (2008), "Illiberal democracy and normative democracy: How is democracy defined in the Americas?" In M. A. Seligson (Org.) Challenges to democracy in Latin American and the Caribbean: Evidence from the AmericasBarometer 2006-2007.

COLLIER, David e LEVITSKY, Steven (1997) "Democracy with adjectives: conceptual innovation in comparative research". Journal of World Politics, v. 49, n. 3, p. 430-451.

CONVERSE, Philip (1964). "The nature of belief systems in mass publics". In D. E. Apter (Org.) Ideology and discontent, Ann Arbor, University of Michigan Press. 
DALTON, Russell. (1999), "Political support in advanced industrial democracies". In P. Norris (Org). Critical citizens: global support for democratic government. Oxford, NY, Oxford University Press. DALTON, Russell. J. (2004), Democratic Challenges, Democratic Choices: The Erosion of Political Support in Advanced Industrial Democracies. Oxford, Oxford University Press.

DALTON, Russel; SHIN, Doh; e JOU, Willy. (2007), Popular conceptions of the meaning of democracy: democratic understanding in unlikely places. Irvine, Center for the Study of Democracy.

DAHL, Robert. (1997), Poliarquia: participação e oposição. São Paulo, EDUSP.

DELLI-CARPINI, Michael e KEETER, Scoot. (1996), What Americans know about politics and why it matters. New Heaven, Yale University Press.

DIAMOND, Larry. (1999), Developing democracy: Towards consolidation. Baltimore, MD, Johns Hopkins University Press.

EVANS, Geoffrey e WHITEFIELD, Stephen (1995). “The politics and economics of democratic commitment: support for democracy in transition societies". British Journal of Political Science, v. 25, n. 4, p. 485-514.

EVANS, Geoffrey e PAULINE, Rose (2007). “Testing mechanisms of influence: Education and Support for democracy in Sub-Saharan Africa”. Afrobarometer Working Paper, v. 75.

FELDMAN, Stanley e ZALLER, John (1992). “The political culture of ambivalence: ideological responses to the Welfare State". American Journal of Political Science, v. 36, n. 1, p. 268-307.

GIBSON, James; DUCH, Raymond. e TEDIN, Kent (1992). "Democratic Values and the Transformation of the Soviet Union". The Journal of Politics, v. 54, n. 2, p. 329-371.

HUANG, Min-Hua; CHANG, Yu-Tzung e CHU, Yun-Han (2008). "Identifying sources of democratic legitimacy: a multilevel analysis". Journal of Electoral Studies, v. 27, n. 1, p. 45-62. 
HUNTINGTON, Samuel. (1991), The Third Wave: democratization in the late twentieth century. Norman, OK, University of Oklahoma Press.

INGLEHART, Ronald e WELZEL, Christian. (2005), Modernization, cultural change, and democracy: the human development sequence. New York, NY, Cambridge University Press.

KOTZIAN, Peter (2011). "Public support for liberal democracy". International Political Science Review, v. 32, n. 1, p. 23-41.

LAGOS, Marta e MORENO, Alejandro. (2013), "Generational change and Democracy in Latin America". In: D. Denemark; R. Niemi; R. Mattes e R. Dalton (Org.), Democratic Attitudes and behavior in Post-Authoritarian Societies.

LINZ, Juan e STEPAN, Alfred. (1996), Problems of democratic transition and consolidation. Baltimore, John Hopkins Press.

LIPSET, Seymour M (1959). "Some Social Requisites of Democracy: Economic Development and Political Legitimacy". American Political Science Review, v. 53, n. 1, p. 69-105.

MAGALHÃES, Pedro (2014). "Government effectiveness and support for democracy”. European Journal of Political Research, v. 53, n. 1, p. 77-97.

MAINWARING, Scott; BRINKS, Daniel; PÉREZ-LIÑÁN, Aníbal (2001). "Classificando Regimes Políticos na América Latina, 1945-1999”. Dados, v. 44, n. 4, p. 645-687.

MATTES, Robert e BRATTON, Michael (2007). "Learning about democracy in Africa: Awareness, performance and experience". American Journal of Political Science, v. 51, n. 1, p. 192-217.

MOISÉS, José Álvaro (2008). “Cultura política, instituições e democracia - lições da experiência brasileira”. Revista Brasileira de Ciências Sociais, v. 23, n. 66, p. 11-44.

MOISÉS, José Álvaro (2010). "Os significados da democracia segundo os brasileiros”. Opinião Pública, v. 16, n. 2, p. 269-309.

MOISÉS, José Álvaro e CARNEIRO, Gabriela (2008). "Democracia, desconfiança política e insatisfação com o regime - o caso do Brasil”. Opinião Pública, v. 14, n. 1, p. 1-42. 
NORRIS, Pippa. (1999), Critical Citizens: global support for democratic government. Cambridge, Oxford University Press.

NORRIS, Pippa. (2011), Democratic Deficit: critical Citizens Revisited. New York, NY, Cambridge University Press.

O'DONNELL, Guillermo (2004). "Why the rule of law matters". Journal of Democracy, v. 15, n. 4, p. 32-46.

OTTEMOELLER, Dan (1998). "Popular perceptions of democracy: elections and attitudes in Uganda". Comparative Political Studies, v. 31, n. 1, p. 98-124.

PEFFLEY, Mark e ROHRSCHNEIDER, Robert (2003).

"Democratization and political tolerance in seventeen countries: a multi-level model of democratic learning". Political Research Quarterly, v. 56, n. 3, p. 244-256.

PUTNAM, Robert (1996). Comunidade e Democracia: a Experiência da Itália Moderna. Rio de Janeiro: Fundação Getúlio Vargas RAUDENBUSH, Stephen e BRYK, Anthony. (2002), Hierarchical linear models: applications and data analysis methods. 2a edição. Newbury Park, CA, Sage.

ROSE, Richard (2002). "Medidas de democracia em surveys".

Opinião Pública, v. 8, n. 1, p. 1-29.

RUSTOW, Dankwart (1970). "Transitions to Democracy: toward a dynamic model". Journal of Comparative politics, v. 2, n. 3, p. 337-363.

SALINAS, Eduardo e BOOTH, John (2011). "Micro-social and Contextual Sources of Democratic Attitudes in Latin America". Journal of Politics in Latin America, v. 3, n. 1, p. 29-64.

SARTORI, Giovanni. (1999), Elementos de Teoria Política. São Paulo, Alianza.

SCHEDLER, Andreas e SARSFIELD, Rodolfo (2007). "Democrats with adjectives: Linking direct and indirect measures of democratic support". European Journal of Political Research, v. 46, n. 5, p. 637-659.

SCHUMPETER, Joseph. (1975), Capitalism, socialism and democracy. New York, Harper Torchbooks. 
VERBA, Sidney., SCHLOZMAN, Kay e BRADY, Henry. (1995), Voice and equality: Civic voluntarism in American politics. Cambridge, MA, Harvard University Press.

YAP, Fiona (2013). "Economic performance and democratic support in Asia's emergent democracies". Comparative Political Studies, v. 46, n. 4, p. 486-512.

ZALLER, John. (1992), The nature and origins of mass opinion. New York, Cambridge University Press.

\section{Resumo}

O presente artigo analisa o impacto de fatores contextuais - o PIB per capita, a qualidade da democracia e os anos ininterruptos de democracia sobre a coesão do sistema de crenças democrático dos latino-americanos. Considera-se um democrata coeso aquele que apoia diferentes princípios democráticos, notadamente: eleições livres e competitivas, separação dos poderes, primado da lei, participação política e tolerância. Utilizamos, para isso, um modelo multinível com dados de opinião pública de 19 países do Barômetro das Américas de 2010. Os resultados indicam que os cidadãos que vivem em países com maior PIB per capita e maior tradição democrática são mais propensos a serem democratas coesos. A qualidade da democracia, por sua vez, não apresentou resultados significativos. Argumentamos que esses achados têm uma importante implicação para a democracia na região.

Palavras-chave: legitimidade democrática, sistema de crenças, apoio à democracia, democracia, qualidade da democracia

\section{Abstract}

This article analyzes the impact of contextual factors - GDP per capita, quality of democracy, and uninterrupted years of democracy - on the cohesion of the democratic belief system of Latin Americans. We consider a cohesive Democrat who supports different democratic principles, notably: the free and competitive elections, separation of powers, the rule of law, political participation and tolerance. We use a multilevel model with public opinion data from 19 countries of the Americas Barometer 2010. The results show that people living in countries with higher GDP per capita and stable democracies are more likely to be cohesive Democrats. 
The quality of democracy, in turn, did not show significant results. We argue that these findings have important implications for democracy in the region.

Keywords: democratic legitimacy, belief system, support for democracy, democracy, quality of democracy

Recebido em 10 de março de 2019

Aprovado em 31 de março de 2019 